\title{
Joint International Physics Summer School: Optics
}

\section{Maria Bondani, Alessia Allevi, Jan Soubusta, Ondřej Haderka}

Maria Bondani, Alessia Allevi, Jan Soubusta, Ondřej Haderka, "Joint International Physics Summer School: Optics," Proc. SPIE 9793, Education and Training in Optics and Photonics: ETOP 2015, 979309 (8 October 2015); doi: $10.1117 / 12.2223057$

SPIE Event: Education and Training in Optics and Photonics: ETOP 2015, 2015, Bordeaux, France 


\title{
Joint International Physics Summer School - Optics
}

\author{
Maria Bondani $^{a}$, Alessia Allevi ${ }^{b}$, Jan Soubusta $^{c}$, Ondřej Haderkac \\ ${ }^{a}$ Institute for Photonics and Nanotechnologies, CNR and CNISM UdR Como, \\ via Valleggio 11, I-22100 Como, Italy \\ ${ }^{b}$ Department of Science and High Technology, University of Insubria, \\ via Valleggio 11, I-22100 Como, Italy \\ ${ }^{c}$ RCPTM, Joint Laboratory of Optics of Palacký University and Institute of Physics of \\ Academy of Sciences of the Czech Republic, Faculty of Science, Palacký University, \\ 17.listopadu 12, 77146 Olomouc, Czech Republic
}

\begin{abstract}
We report on the organization and realization of the "Joint International Physics Summer School - Optics" devoted to High-School students. The idea of the School is to teach Physics through high-level experimental activities, suitably supported by introductory lectures and complemented by data analysis. The School is also open to the participation of a number of teachers, as an opportunity of refreshing their knowledge and increasing their experimental skills. Students and teachers are directly involved in the experimental activities. The aim of the activity is to stimulate students curiosity and interest and help them decide whether a future job career in Science could be suited for them. The School is organized in two weeks: the first in June-July in Como (Italy) at the Department of Science and High Technology and the second at the end of August in Olomouc (Czech Republic) at the Joint Laboratory of Optics. Two editions of the Summer School took place in 2013 and 2014 (overall 40 students and 3 teachers from Italy, 9 students from Czech Republic) and the third one will be in 2015. The first week of the School is devoted to introductory lectures (theoretical and experimental) to consolidate students' and teachers' knowledge of basic optics. The second week is devoted to several advanced experiments in linear, nonlinear, classical and quantum optics, performed in research laboratories. During the last day of the School, students are required to give a presentation of the results obtained during the experimental sessions.
\end{abstract}

Keywords: High-school students, Summer School, International cooperation and co-development in education and training

\section{INTRODUCTION}

The recent increases in the technological character of the workplace appear likely to continue, leading to increasing the number of individuals who should learn something about science. For many of these people, understanding the character of science, including learning new ways to think about and analyze the physical world, is an essential component of what they need to learn. In one sense, the growth of other sciences and technology is putting pressure on physics. Despite incredible opportunities for new research, Physics Departments around the world are beginning to have some difficulties in recruiting students. In some countries, the number of physics majors has stopped growing, in others it has begun to decline. European Commission is working against this trend by supporting projects on STEM disciplines. ${ }^{1}$ Investigations carried out to try to understand the reasons for this decline show that science subjects are often experienced by students as too difficult and unattractive as to content presentation, which almost always occurs through lectures. Experimental activities are more than often neglected. In this scenario, High-School teachers need to figure out exactly what they can usefully teach to young students and how to do it effectively in the short time they are in a physics class.

The Joint Summer School addresses this problem by shifting the method of teaching and learning towards a true experimental approach guided by scientists in research laboratories. In fact, the ability of Physics in explaining

Further author information: (Send correspondence to M.B.)

M.B.: E-mail: maria.bondani@uninsubria.it, Telephone: +39031 2386252

Education and Training in Optics and Photonics: ETOP 2015, edited by Eric Cormier, Laurent Sarger Proc. of SPIE Vol. 9793, 979309 · @ 2015 SPIE, IEEE, OSA, ICO · doi: 10.1117/12.2223057 
natural phenomena is itself a source of wonder and fascination for all human being and especially for young people, but it is only when this appeal takes the form of a concrete person (a scientist) that it can be experienced as a possibility for the future. For this reason it is a common practice in schools to take pupils to visit laboratories, universities and museums to meet researchers and experts, or to host lectures and experimental demonstration from academic researchers. ${ }^{2}$ The first objective of the Summer School is to sustain and increase young people's interest toward Physics by a direct interaction with researchers during a true experimental research activity. The second aim of the School is to offer school teachers the possibility of keeping in contact with scientific research and not losing the passion for the subjects they have to teach.

For all these reasons we propose to boys and girls an experimental activity aimed at developing their scientific attitudes and at teaching them how to conduct a work in team in a correct balancing of collaboration, competitiveness and independence. The style of the Summer School is somehow similar to a previous Summer School organized at University of Insubria for PhD and post-doc students. ${ }^{3}$ Together with students, teachers will learn new teaching strategies and, by working in the research laboratories side-by-side with their students, they will become more aware of students difficulties in understanding physical problems. In fact, we expect high-school teachers will experience almost the same learning difficulties as students in the context of research activities.

Besides stimulating students curiosity and interest toward Physics, we expect that the Summer-School activities will help them understand if a future career in the scientific world could be suited for them.

The physics topics chosen for the Summer School are connected with Optics, because optical subjects are particularly suited since the mathematical knowledge needed to understand basic optics concepts (geometric and wave optics) is affordable for high-school students. When a more specific content is required to perform the experiments, it will be introduced during the lectures in a suitable way. Moreover, optical effects are at the basis of many natural phenomena (rainbow, images, color of the sky) and, at the same time, of many advanced technological applications (optical fibres, lasers, transmission of information, non-invasive medical diagnostics...), and this makes the topics appealing by themselves even for future medical doctors, chemists or engineers. The academic Institutions involved in the organization of the Summer School are specifically involved in scientific research in Optics from many points of view.

In the following sections we present the method of the Summer School and its implementation during two editions, together with some preliminary evaluation of the activities.

\section{METHODOLOGY}

The main idea of the Joint International Physics Summer School - Optics is to offer an experimental program on Optics by connecting physics research laboratories in two different Countries, namely Italy and Czech Republic, which will host two weeks of experimental full-immersion activities for students who have attended the second to last year of a High School. The Summer School is also open to the participation of a number of Physics teachers from the same High Schools, who have the opportunity of refreshing their knowledge and to increase their experimental skills. In fact, both students and teachers are directly involved in the scientific research of the groups organizing the School and can directly experience a bit of their true activities, including the necessity of reporting obtained results. Many professors, researchers and tutors from the two organizing Institutions were involved in the organization and realization of the Summer School, in order to assure a low ratio participants/teachers.

As to the logistic organization of the Summer School, in the past two editions, the first week in Como was not residential, since the students came from the neighborhood of the Department of Science and High Technology of Insubria University, while the second week in Olomouc was of course residential. In more detail, Italian students and accompanying persons were hosted in the students' dormitory close to Joint Laboratory of Optics. Students' expenses for travel, board and lodging were partially supported by the program for orientation to the choice of University courses of Insubria University.

In the past two years (2013 and 2014), the first week of the School was held in Italy (Como) and attended by Italian students only, while the second week was held in the Czech Republic (Olomouc) and was attended by Italian students in 2013 and by Italian and Czech students in 2014.

In Figs. 1 and 2 we present the program of the first edition of the School in 2013, which was substantially kept equal also in the 2014 edition. 
First week: Insubria University (Como) - July 1-5, 2013

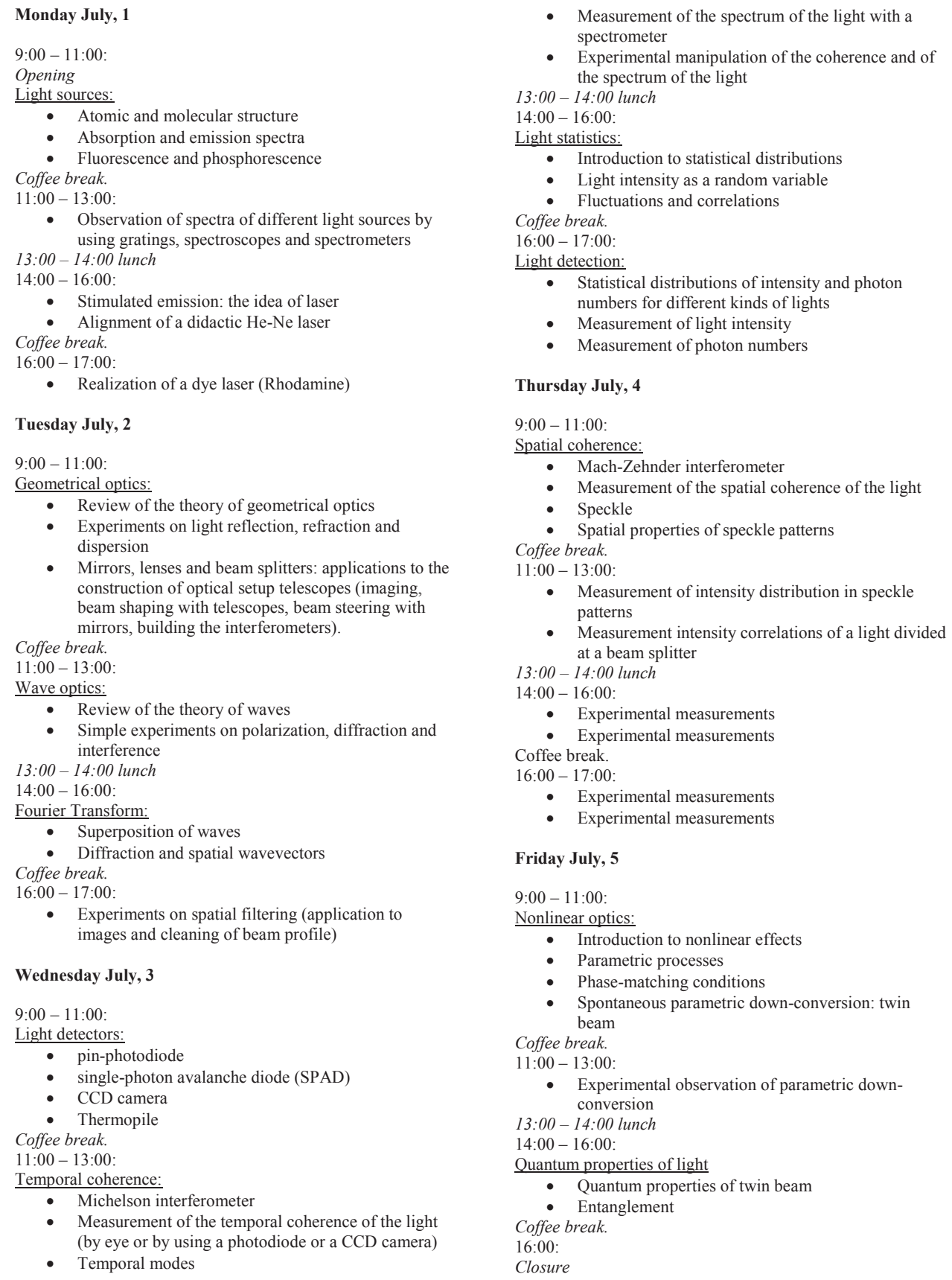

Figure 1. Program of the first week of the International Summer School in Como (2013).

The first week held in Como, was organized in five full days (see Fig. 1), from 9 am to 17 pm, with a break for lunch. The program is organized to cover a large part of the topics of optics, from ray optics to quantum optics, passing through wave optics, spectroscopy, light sources and so on. The program is rather ambitious and of course not all the topics could be developed in their full depth, but the effort was to address the core of each of them in a quantitative way. Each topic was presented through frontal lectures immediately followed 


\section{Second week: Palacky University (Olomouc) - August 26-30, 2013}

PHASE 1: On Monday and Tuesday the students will have theoretical lectures in the morning (all together) and experimental demonstrations in the afternoon (divided in four groups) according to the following scheme:

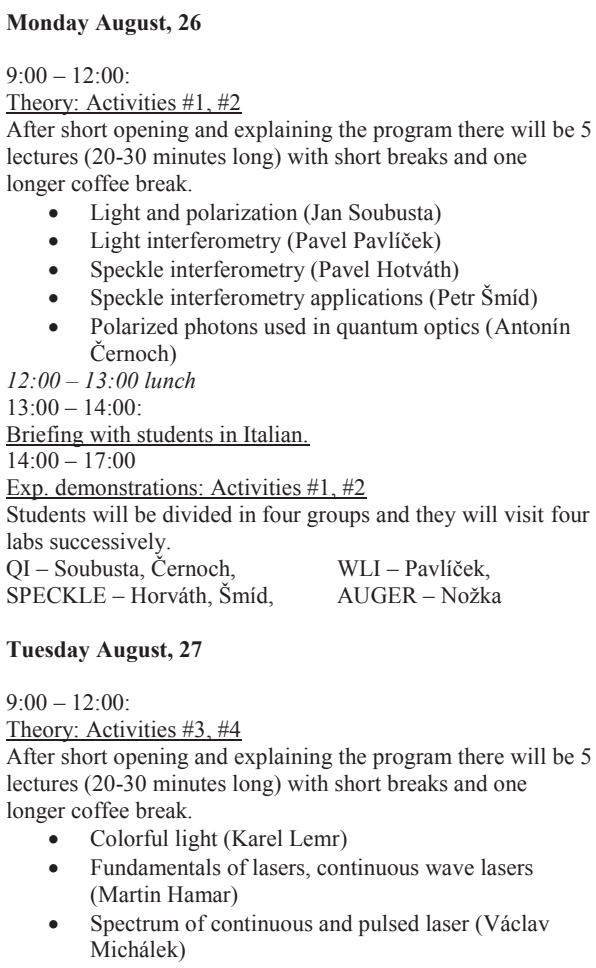

- Construction of pulsed lasers and amplifiers (Martin Hamar)

- Nonlinear-optical processes and devices (Radek Machulka)

12:00 - 13:00 lunch

13:00 - 14:00

Briefing with students in Italian.

14:00 - 17:00:

Exp. demonstrations: Activities \#3, \#4

Students will be divided in four groups and they will visit

successively four labs.

NLO - Machulka, Lemr FEMTO - Hamar,

LASER - Chmelíčková, Řiháková,

MICROSCOPE - Šebestová, Tomáśtík

Tuesday evening

Each activity (\#1-\#4) will offer two student topics. Students will be divided in eight groups. One person will be solving only one selected topic. There will be at most three students at any topic and they will prepare together one common presentation for Friday final meeting.

\#1 Interferometry

A. White-light interferometry (Pavel Pavlíček)

B. Speckle interferometry (Petr Šmíd + Pavel Horváth)) \#2 Light properties

A. How to change and measure the polarization of the light (Jan Soubusta)

B. Two photon interference (Antonín Černoch) \#3 Non-linear parametric processes

A. Laser pumped up-conversion, second-harmonic generation (Radek Machulka)

B. Measuring colours (Karel Lemr) \#4 Pulsed laser sources

A. Measurement of time profile of chopped continuous laser (Martin Hamar)

B. Laser light intensity stabilization (Václav Michálek)

PHASE 2: On Wednesday and Thursday the students will stay in one of the labs they visited the days before and perform an experiment including measurements, data analysis and final data presentation experimental demonstrations in the afternoon according to the following scheme:

Wednesday August, 28

9:00-12:00:

Experiments \#1A, \#1B, \#2A, \#2B, \#3A, \#3B, \#4A, \#4B

(At maximum three students at any topic)

12:00-13:00 lunch

13:00 - 14:00:

Briefing with students in Italian

14:00-17:00:

Experiments
Thursday August, 29

9:00-12:00:

Experiments \#1A, \#1B, \#2A, \#2B, \#3A, \#3B, \#4A, \#4B

(At maximum three students at any topic)

12:00 - 13:00 lunch

13:00 - 14:00

Briefing with students in Italian.

14:00 - 17:00:

Interpretation of data and preparation of presentations

PHASE 3: On Friday each group of students will present the results of the performed experiment to the other groups.

Friday August, 30

9:00-12:00:

Presentations

15-minute presentations of five topics \#1A - \#3A

12:00 - 13:00 lunch
13:30-15:00:

Presentations

15-minute presentations of three topics \#3B - \#4B

15:00:

Closing the workshop

Figure 2. Program of the second week of the International Summer School in Olomouc (2013).

by experimental sessions aimed at implementing and discovering the presented subjects in practice. Note that part of the physical content discussed in the School (e.g. ray and wave optics) is usually included in standard High-School programs, while some topics (e.g. non-linear and quantum optics) are new for students.

The students were organized in small groups (3-4 people) so that each of them could have the opportunity of a true involvement in the experimental work. Students had to prepare the experiments, to take the measurements 
required to characterize the systems and to make data analysis. Some of the topics are too advanced to be directly experimented by students, so that the experiments are prepared by the teacher assistants and students are only involved in the measurements. This is the case, for instance, of the observation and measurements of second harmonic generation and of the quantum properties of twin beams.

Also the second week in Olomouc is organized in five full days (see Fig. 2) but it follows a different approach. During this week the official language of the School is English. Nevertheless the students have always possibility to ask questions and to solve urgent tasks in their native language during meetings with organizers and accompanying persons.

During the first two days of the second week, a number of advanced topics are presented by specialized researchers to all the students. The topics are chosen according to the experimental activities going on in the research laboratories of the Joint Laboratory of Optics. After the theoretical presentations, the students are taken to the different laboratories to see the implementation of the different experimental techniques in demonstrations given by the researchers themselves. At the end of the second day, the students form small groups (2-3 people) and choose one of the proposed experimental activities. During the third and fourth days of the week, each group works in the laboratory under the supervision of the specialized researchers, taking part in a true experiment and exploiting the knowledge they have achieved to make measurements and analyze data. In the final day of the week, each group is asked to present the results of their experimental activities in a brief presentation in English.

\section{RESULTS AND DISCUSSION}

During the 2013 edition of the School, 23 students (9 girls and 14 boys) and two high-school teachers (a woman and a man) took part in both weeks of the School, while in 2014, 14 students (8 girls and 6 boys) and one teacher (a man) where involved. The reduced number of participants from Italy in the second edition was motivated by the participation of 9 Czech students ( 2 girls and 7 boys) who joined the second week of the School. We note that a large number of girls took part in the School, which is rather unusual for Physics courses.

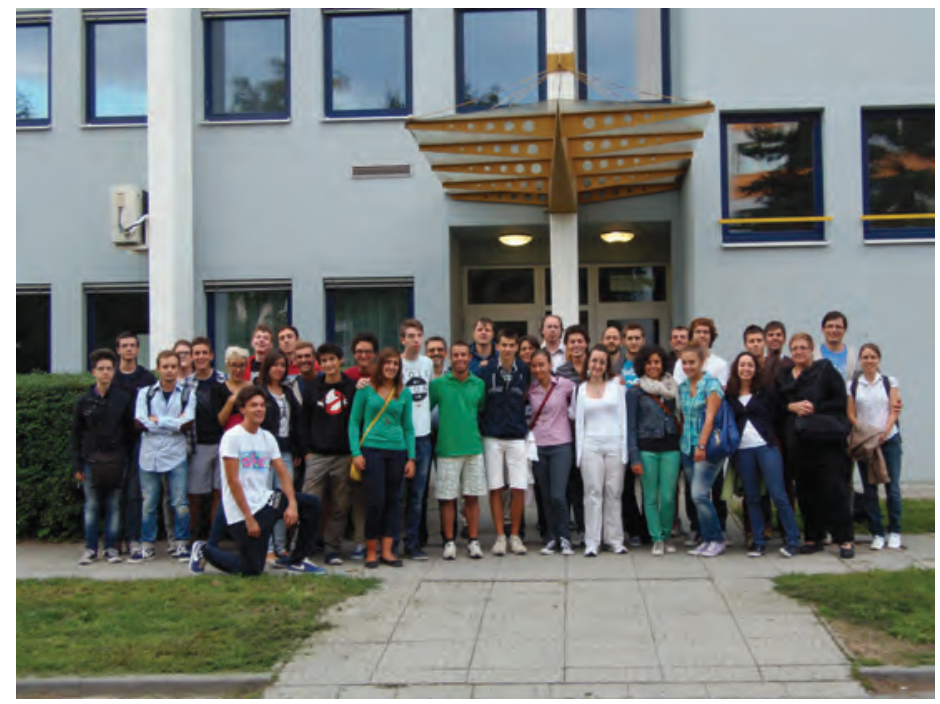

Figure 3. Participants in the International Summer School in Olomouc (2013).

All the students taking part in the two editions of the Summer School, except one, came from scientifically oriented High Schools and were strongly motivated towards the study of Physics even if not all of them usually got brilliant results in science subjects. In fact, the selection of the participants was made on the basis of personal motivation and interest towards Physics subjects and not on the basis of their educational performance. The students who participated in the School in 2013 are now attending University courses, and the large part of them took scientific subjects (Physics, Chemistry, Material Science, Engineering, Medicine). It is not clear if the 
Summer School helped them in the decision for the university, but for sure it gave them some more insight into scientific work.
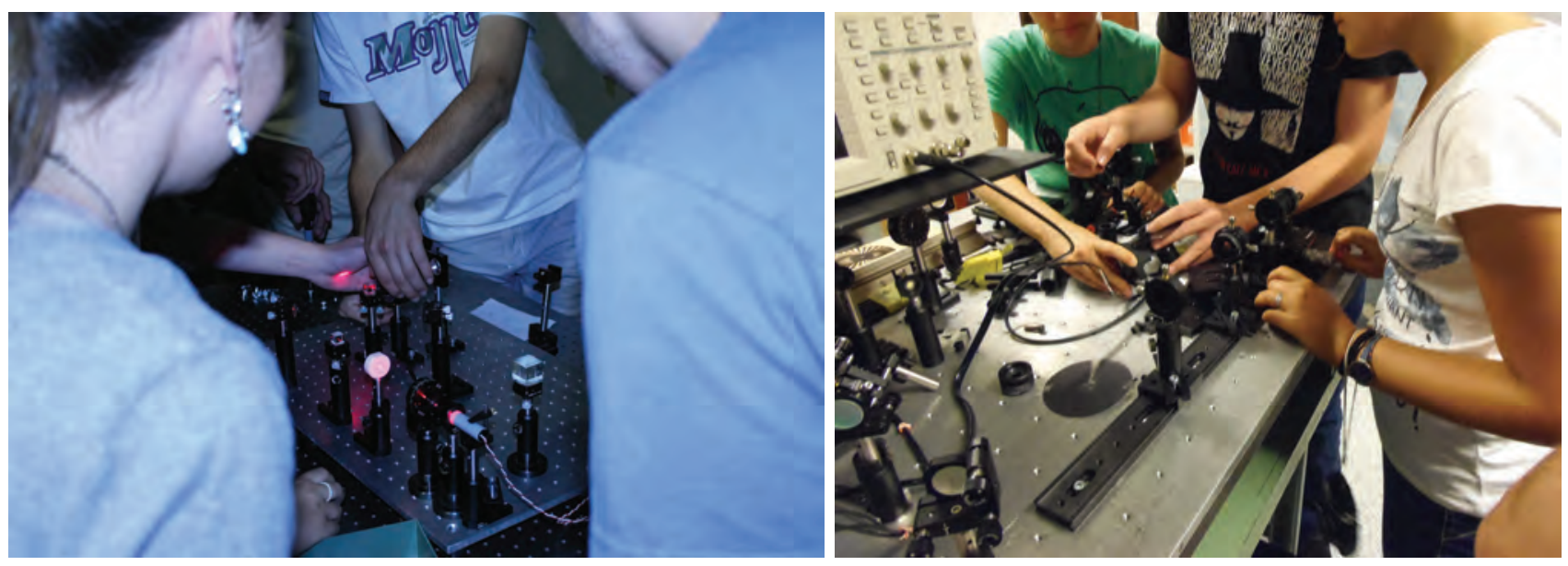

Figure 4. Laboratory session in Como (left) and Olomouc (right) during the 2013 edition of the International Summer School - Optics.

We conducted a number of interviews with students to investigate their personal perception of the Summer School activities. Students particularly appreciated the possibility of working side-by-side with active researchers and to experience some autonomy in the work. Moreover they declared a better understanding of the method of scientific research. In particular, the students positively evaluated the strict connection between the topics proposed theoretically and their experimental realization, the possibility of critically revise the subjects they studied at school, the use of advanced scientific instrumentation, the independent approach to the realization of the experiments and the experience in an international environment.

The use of a foreign language (English) as a communication tool was a plus of the School and no substantial problems came from this necessity. The final presentations were all high quality even if for all of them it was the first occasion to give a public presentation.

As to teachers, all of them declared a deep satisfaction in the School experimental activities, even if, as expected, they experienced the same kind of difficulties as students. In fact, for most teachers the familiarity with the scientific activity is far away in time and the School acted as a refresh of their knowledge and skills.

Finally, organizing the Summer School gave a lot of stimulating inputs also to the involved researchers, who had to critically re-think at their work in order to present it to students in an adequate but scientifically sound way.

\section{CONCLUSIONS}

The Summer School will be proposed again the next summer (2015) and will involve about 30 students, both Italian and Czech. The program of the two weeks will be nearly the same. We hope that in the future editions of the School, some students from Olomouc could take part in the Italian part of the School. We also hope that this collaboration between two different laboratories could be extended to other European groups thus building a network of laboratories involved in Physics education.

\section{ACKNOWLEDGMENTS}

The Authors acknowledge the economical support of University of Insubria. 


\section{REFERENCES}

[1] http://www.eun.org/about/projects/stem

[2] Bondani, M., Allevi, A., Nardo, L. and Favale, F., "The 'LuNa' Project: experimental didactic modules exploiting portable setups to teach optics in Primary and Secondary Schools," 12th Education and Training in Optics and Photonics Conference, edited by Manuel F. P. C. Martins Costa, Mourad Zghal, Proc. of SPIE 9289, 92892D (2014).

[3] Favale, F., Zecca, L., Nigris, E. and Bondani, M., "'STELLA 2011 - School for Training in Experiments with Lasers and Laser Applications': Short-term evaluation by quantitative methods," The European Physical Journal Special Topics 199(1), 195-212 (2011). 